\title{
Organizational Commitment Literature Review
}

\author{
Kai Zhang \\ Nanjing University of Science and Technology, Nanjing 210094, China \\ 1260955606@qq.com
}

Keywords: Organizational commitment; Summary

\begin{abstract}
Organizational commitment is an important research field in organizational behavior. It has good predictive ability on turnover and absenteeism. This paper summarizes the related research about the organizational commitment both at home and abroad, sorts out and concludes the connotation of the organizational commitment, the forecast variables of the organizational commitment and the school-based variables, the measurement of the organizational commitment, the prospect of the organizational commitment and so on, and points out that the lack of research on organizational commitment and future research direction of organizational commitment.
\end{abstract}

\section{The connotation of organizational commitment}

From a single-dimensional perspective, organizational commitment was first proposed by Howard S. Becker (1960), who argued that organizational commitment is an increase in the unilateral input of organizational members to the organization, fearing that a large "sinking cost" would result from the cessation of investment. And have to continue to stay in the psychological phenomenon of the organization [1]. Buchanan (1974) believes that organizational commitment is the recognition of organizational members' goals and values, and the individual's recognition and involvement in specific organizations [2]. Mowday, Steers, and Porter (1979) argue that organizational commitment refers to the degree of personal acceptance and engagement of the organization, an emotional dependence [3].

From a multidimensional perspective, the most recognized is the factor model proposed by Meyer and Allen. Meyer and Allen (1984) proposed a two-factor theory of emotional commitment and sustained commitment based on field research and summarizing previous experiences [5]. Since then they have put forward a normative commitment [6]. O'Reilly and Chatmen (1986) believe that organizational commitment refers to the organization of employees and organizations' "psychological contract", which includes a mixture of compliance, identification, and internalization of different components [7]. The five-factor models of Chinese employee organization commitment are: emotional commitment, ideal commitment, normative commitment, economic commitment and opportunity commitment [8]. Wang Chong ming (2003) believes that organizational commitment refers to employees' sense of identity with specific organizations and their goals, and hopes to maintain their status as members of the organization [9]. Through analysis, it can be argued that organizational commitment is a state in which members of an organization remain in the organization and work for it. 


\section{Predictors and calibration variables for organizational commitment}

\subsection{Predictors of organizational commitment}

As organizations commit to multiple dimensions, the factors that influence organizational commitment are diverse. Combined with the relevant research of scholars at home and abroad, this paper starts from two aspects: internal and external.

Internal factors refer to factors related to the members of the organization itself, such as age, gender, and education level. Curivan DB (1999) argues that individual satisfaction and dissatisfaction with work also has a significant impact on organizational commitment [10]. Chinese scholar Cui Xun (2003) believes that the gender, age, education, marital status, hukou and other demographic variables and positions, consecutive service years, number of resignations, promotion probability, promotion times and other job-related variables have significant organizational commitment to employees. Impact. Liu Xiaoping (2003) concluded that there is a close relationship between organizational commitment and age, seniority, and education level. Although it is positively related to age and seniority, its nature is different.

From the perspective of external factors, it mainly includes organizational factors and work status factors. Berger (1979) believes that factors affecting organizational commitment will be influenced by the background of the work, and what kind of mentality the company will treat the members of the organization, and what kind of mentality the employees will treat the enterprise. Dunham, JA Grube (1994) found through research that work autonomy, challenges, and the skills that employees learn from each other are positively related to organizational commitment. Chinese scholars Liu Xiaoping and Wang Chongming (2002) analyzed the influencing factors of organizational commitment through scenario simulation experiments. He believed that (1) organizational commitment has a close relationship with organizational support; (2) the number of opportunities available to employees It also has an impact on its organizational commitment; (3) the interaction between organizational support and choice opportunities on organizational commitment; (4) in the organizational commitment causality model, the factors affecting the organizational commitment components are different; (5) In the organizational commitment causality model, the impact of each component of the organization's commitment on the outcome variables is different. Emotional commitment and sustained commitment have significant influence on the retention tendency and turnover intention.

\subsection{Calibration variables of the organization's commitment}

The calibration variable of the organization's commitment means that the organization's commitment can produce certain results for the members of the organization, mainly reflected in the two aspects of job performance and separation.

Steers (1977) found that job characteristics and work experience affected organizational commitment. In addition, organizational commitment is related to the organization's work intentions, a strong desire, and attendance, and there is no direct relationship with job performance. Keller (1997) argues that the higher the correlation between wages and job performance, the higher the correlation between continued commitment and performance; the clearer individual expectations, the fewer conflicts, and the higher the correlation between emotional commitment and performance. Chinese scholars Hu Weipeng and Shi Kan (2004) pointed out that there may be mediating variables between organizational commitment and job performance, the clarity of work objectives may also act as a moderator between emotional commitment and performance [4].

Organizational commitments are closely related to employees' turnover intentions, but most of the literature on the study of turnover behaviors mostly regards work attitudes (such as job 
satisfaction, organizational commitment) and demographic variables (such as age, marital status) as employee turnover intention and voluntary. An important predictor of turnover behavior. Meyer (1997) found that the different factors of organizational commitment and the degree of separation are different. Most scholars believe that the stronger correlation with turnover is the emotional commitment, because the individual's emotions are constantly changing. Lincoln (1990) argues that job satisfaction is an antecedent variable of organizational commitment, mainly because members' emotions about a job are transferred to the entire organization. Blau and Boal (1987) found that employees with higher levels of commitment had lower absenteeism and turnover rates through surveys of members of the insurance industry.

\section{The measurement of organizational commitment}

There are still many tools for measuring organizational commitments at home and abroad. This article mainly introduces the following four types:

OCQ (Organization Commitment Questionnaire) scale. Developed by Mowday and Porter (1979), the scale is the first tool to measure organizational commitment. It is measured at three levels, namely, the recognition and acceptance of the organization, the degree of commitment to the organization, and the willingness to continue to retain the members of the organization.

PAI (Psychological Attachment Instrument) scale. The scale was compiled by Oreilly and Chatman (1986). He measured organizational commitments through three dimensions: compliance, identity, and internalization. The scale has 12 items.

Three-factor scale. The scale was compiled by Meyer and Allen (1997). He measures organizational commitment through three levels: emotional commitment (ACS), normative commitment (NCS), and continued commitment (CCS). There are 8 items, which were later revised to 6 items.

The five-dimensional organizational commitment scale proposed by Chinese scholar Ling Wenzhao et al. (2000), which is divided into five aspects: emotional commitment, ideal commitment, opportunity commitment, economic commitment and normative commitment; the results of the research, the questionnaire The reliability of the test is above 0.7 , which is credible; and the internal consistency reliability of each factor is above 0.7 , which is credible.

\section{Prospects for the future}

\subsection{On the basis of enriching the connotation of organizational commitment, it is necessary to accurately define its connotation}

The development of the connotation of organizational commitment has experienced the development from a single dimension to multiple dimensions, and its connotation has been enriched to a large extent, but it lacks a great step in quality. For example, meyer and Allen's three dimensions organize commitments, and we should strengthen their accuracy and structure.

\subsection{Measure the variables from multiple angles}

Most of the existing researches define and measure organizational commitments from the attitudes and individuals of the organization members, while ignoring other aspects of organizational commitment. We should pay more attention to the relationship between organizational members and organizational members, organizational members and organizations. . And the measurement of each dimension should not only stay at the level of "whether it is affected", but also reflect the level of "how much influence". 


\subsection{Strengthen academic exchanges}

In the past, because the research objects, research methods and cultural backgrounds of domestic and foreign researchers are different, the research conclusions are often not the same. For Chinese scholars, we should communicate more with domestic and foreign scholars. Their advanced research techniques and methods, starting from the reality of our country, to develop a method suitable for China's situation.

\section{References}

[1] Howard S.Becker.Notes on the Concept of Commitment[J].American Journal of Sociology , 1960 , 66 (1) :32-40

[2] B Buchanan. Building Organizational Commitment: The Socialization of Managers in Work Organizations. Administrative Science Quarterly, 1974 , 19 (4) :533-546

[3] RT Mowday, RM Steers, LW Porter. The measurement of organizational commitment[J], Journal of Vocational Behavior , 1979 , 14 (2) :224-247

[4] Hu Weipeng, Shi Kan. Progress and Prospect of Organizational Commitment[J]. Advances in Psychological Science, 2004, 12(1): 103-110

[5] JP Meyer,NJ Allen. Testing the "side-bet theory" of organizational commitment: Some methodological considerations[J]. Journal of Applied Psychology, 1984 , 69 (3) :372-378

[6] JP Meyer, NJ Allen. A three-component conceptualization of organizational commitments[J]. Human Resource Management Review, 1991, 1(1), 61- 89

[7] O' Reilly C F , Chatmen J.Organizational Commitment and Psychological Attachment: The Effects of Compliance, Identif ication, and Internalization on Prosocial Behavior.Journal of Applied Psychology, 1986, 71:492-499

[8] Ling Wenbiao, Zhang Zhican, Fang Yiluo. Research on the structural model of Chinese employee organizational commitment. Journal of Management Science, 2000, 3 (2): 76-81

[9] Wang Zhongming. Organizational Behavior [M]. Beijing: Petroleum Industry Press, 2003

[10] Currivan DB.The causal order of job satisfaction and orga-nizational commitment inmodels of employee turnover [J] . Human Resource Management Review , 1999 , 9(4): 495-524 